\title{
Perceived Burden in Caregivers of Children with Autism Spectrum Disorder
}

\author{
Shrijana Pandey, ${ }^{1}$ Chandrakala Sharma ${ }^{2}$ \\ ${ }^{1}$ Department of B.Sc. Nursing, Kathmandu Medical College, Kathmandu University, Kathmandu, Nepal, 2 \\ Nursing Campus Maharajgunj, Institute of Medicine, Tribhuvan University, Kathmandu Nepal.
}

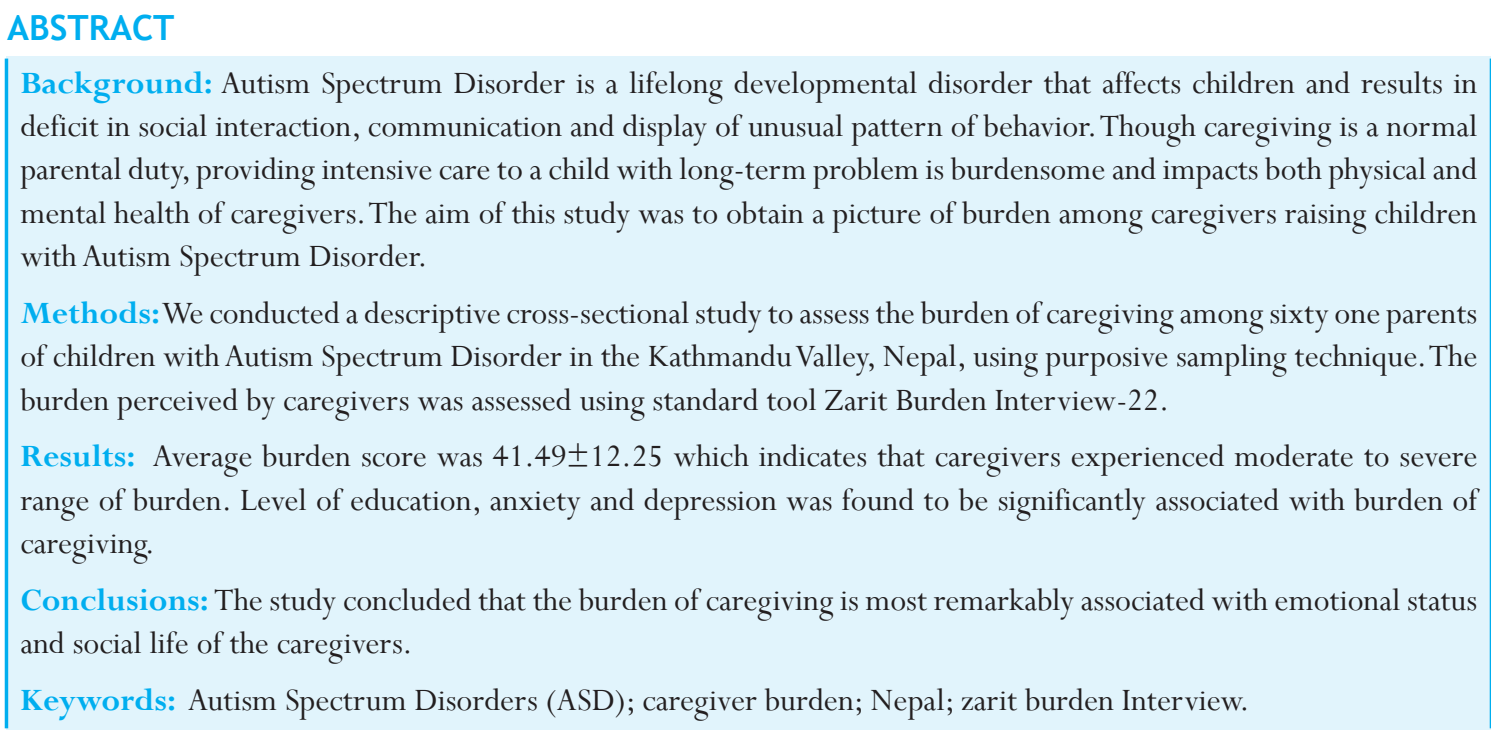

\section{INTRODUCTION}

Autism Spectrum Disorder (ASD) is a lifelong developmental disability that includes deficits in social interaction, communication and restricted, repetitive patterns of behavior, interests or activities. A child with ASD may show unusual interests and behaviors and may have problems with sleeping and eating. ${ }^{1}$ In recent years, the awareness regarding ASD has improved globally resulting in a rise in global prevalence of ASD. ${ }^{2}$ In Nepal;no study has been done to assess the prevalence of ASD. ${ }^{3}$ However, a study carried out to assess the psychiatric morbidity amongst children attending child guidance clinic in Nepal found that around 10\% ( $n=539)$ of the children suffered from pervasive developmental disorder. Among these children $3.7 \%$ had a diagnosis of ASD. ${ }^{4}$ Caring for children with ASD is challenging as caregivers have to face difficulties in dealing with the unusual behaviors of their child, teaching them to interact, teaching them basic life skills, protecting them from danger and preparing for their transition into adulthood. ${ }^{5-7}$ Due to this multidimensional requirement of caregiving, caregivers experience tremendous stress, misconceptions, feeling of guilt and self-blame regarding child's disorder. ${ }^{8}$ As parents' well-being could positively influence caregiving and thus decrease the burden of care $^{9,10}$ studies focusing on caregivers are necessary. The researchers were thus, interested in carrying out a study to assess the extent of burden perceived by caregivers raising a child with ASD.

\section{METHODS}

A descriptive cross sectional study design was used to assess the burden perceived by the caregivers. The data was collected at Autism Care Nepal Society and at the residences of the caregivers as per their convenience. The study population consisted of caregivers either father or mother who was caring for a child with ASD. The researchers agreed to include the caregivers residing in Kathmandu valley who were registered at or were attending Autism Care Nepal Society and had a child of upto 19 years diagnosed with ASD by either a psychiatrist, psychologist or a pediatrician. From the registration list of Autism Care Nepal Society, all the caregivers residing in Kathmandu Valley were sorted out and they were approached for data collection. Sixty one caregivers, out of around 85 registered to be living
DOI: http://dx.doi.org/10.3126/

inhrc.v16i2.20308 
in Kathmandu valley, were chosen purposively to be included in our study.

The study included questions related to sociodemographic details of caregiver and child, general information on ASD, psychological distress (anxiety and depression) and caregiver burden. The questions related to socio-demography and general information of ASD was prepared by the researchers on the basis of extensive literature review and consultation with advisor/experts. For assessing psychological distress (anxiety and depression) standardized tool called Hopkin's Symptom Checklist-25 was used. A cut - off score of more than or equal to 1.75 of the mean score was used to identify a case of either anxiety or depression. ${ }^{11-13}$ Caregiver burden was assessed using Zarit Burden Interview - 22 which is composed of 22 items that reflect how a person feels when they are taking care of another person. The scale for first twenty one questions include five categories of responses ("Never," "Rarely," Sometimes," "Quite frequently," Nearly always", rated 0 to 4 , respectively). However, the last question i.e. question number 22 include five response categories ("not at all”, "a little", "moderately", "quite a bit", "extremely" rated 0 to 4, respectively). Zarit Burden Interview -22 is scored according to the presence or intensity of an affirmative response, and measures the caregiver's health, emotional well-being, social and family life, finances, and the relationship between the caregiver and child. ${ }^{14}$ The total score range from 0 to 88 . A total score is calculated by the sum of all the item scores and high scores indicate a higher level of burden. The translation and linguistic validation of Zarit Burden Interview -22 was done according to the directions provided by Mapi Research Trust, France. After consultation with subject expert, the term "your relative" in Zarit Burden Interview -22 was replaced by "your child" with permission from the trust for its applicability in the present study.

In our study, the level of burden was categorized according to the scores obtained by the caregivers and included:Little or no burden (0 - 21); Mild to moderate burden(21 - 40); Moderate to severe burden (41 - 60); Severe burden $(61-88) .{ }^{15,16}$ Reliability of the tool in terms of internal consistency was assessed by Cronbach's alpha and it was found to be 0.850 for Zarit Burden Interview -22 and 0.933 for Hopkin's Symptom Checklist-25.

Ethical clearance was obtained from concerned authorities and institutional review board of Institute of Medicine (IOM), Nepal. A written informed consent was obtained from all the caregivers included in the study. Code numbers were used to maintain confidentiality of the information. Data was collected using interview method and when both parents were present at the time of interview, the caregiver who spent more time in child care was included. Data could not be collected from nine of the approached caregivers. Out of around 85 registered caregivers contacted for the study, three caregivers denied from participation, 4 caregivers had moved out of study site and remaining 2 caregivers didn't answer the phone. The study period was of one year.For the analysis of obtained findings, Man Whitney $U$ was used to assess the association between variables since the study followed non-probability sampling technique and contained small sample size.

\section{RESULTS}

Of the 61 caregivers, 58 were mothers of the children while the remaining three were fathers. At the time of the interview, the mean age of the caregivers was $33.6 \pm 5.1$ years and that of the children was $7.9 \pm 3.5$ years. Sixty- nine percentages of the caregivers had attained education of above higher secondary level and $59.0 \%$ were unemployed (i.e. homemakers, social worker and student). Almost all (98.4\%) had no significant family history of the disorder. More than half $(60.7 \%)$ of the children were admitted to schools designed for special children. In regard to psychological distress, $33.0 \%$ of caregivers had clinically significant symptoms of anxiety while $24.6 \%$ had symptoms of depression.

\section{Table 1. Socio-demographic characteristics.}

Socio-demographic Frequency Percentage characteristics

\begin{tabular}{|c|c|c|}
\hline \multicolumn{3}{|c|}{ Expenses for the child(per month) } \\
\hline$<5$ thousands & 21 & 34.4 \\
\hline $5-10$ thousands & 29 & 47.5 \\
\hline$>10$ thousands & 11 & 18.0 \\
\hline \multicolumn{3}{|c|}{ Median $=7$ thousands } \\
\hline \multicolumn{3}{|l|}{ Training received } \\
\hline Yes & 48 & 78.7 \\
\hline No & 13 & 21.3 \\
\hline \multicolumn{3}{|l|}{ Sex of the child } \\
\hline Male & 47 & 77.0 \\
\hline Female & 14 & 23.0 \\
\hline
\end{tabular}

Mean Age at diagnosis (in years) $=4.25 \pm 2.42$

Mean Duration of diagnosis(in months) $=44.31 \pm 34.69$

Mean Hours spent in care per day $=10.04 \pm 3.90$

Table 1 show that almost half of the caregivers (47.5\%) spent 5 to 10 thousands Nepali rupees per month in the care of their autistic child. More than three fourth of the caregivers $(78.7 \%)$ had received some form of train- 
ing about rearing a child with ASD and seventy-seven percentages of the children were male.

Table 2. Level of burden among caregivers ( $n=61)$. Level of burden according to scores obtained Frequency Percentage

\begin{tabular}{lcc}
\hline Little or no burden $(0-20)$ & 2 & 3.3 \\
$\begin{array}{l}\text { Mild to moderate } \\
\text { burden(21-40) }\end{array}$ & 29 & 47.5 \\
$\begin{array}{l}\text { Moderate to severe burden } \\
(41-60)\end{array}$ & 26 & 42.6 \\
$\begin{array}{l}\text { Severe burden }(61 \text { and } \\
\text { above) }\end{array}$ & 4 & 6.6 \\
$\begin{array}{l}\text { Mean Burden Score } \pm \text { S.D. } \\
=41.49 \pm 12.25\end{array}$ & & \\
$\begin{array}{l}\text { Coefficient of variance } \\
=29.5 \%\end{array}$ & & \\
\hline
\end{tabular}

Table 2 shows that the average burden score of caregivers fell in moderate to severe category and there was a variance of $29.5 \%$ in the level of the burden perceived by the caregivers.

Table 3 shows that the overall burden was higher among caregivers who had anxiety and depression than those who didn't have it. Specifically, the burden was higher in all of the four domains except in the domain of finances. Excluding the financial domain, the association between burden in all other domains and psychological distress was found statistically significant.

Table 4 shows that the caregivers with higher level of education were less burdened due to caregiving than those with lower level and the finding was significantly associated with overall burden and burden in domain of finance and control of life. Age and employment status of caregivers, age and sex of the child, hours spent in caring for the child every day and status of received training on caring a child with ASD had no significant association with burden.

Table 3. Association between psychological distress (Anxiety, Depression) and burden across different domains.

Domains of Zarit Burden Interview -22

\begin{tabular}{|c|c|c|c|c|c|c|c|}
\hline \multirow[t]{2}{*}{ Variables } & \multirow[t]{2}{*}{$\mathrm{n}$} & \multirow[t]{2}{*}{ Total Scores } & \multirow[t]{2}{*}{ BR } & \multirow[t]{2}{*}{ EW } & \multirow[t]{2}{*}{ SF } & $\mathrm{FI}$ & LC \\
\hline & & & & & & \multicolumn{2}{|c|}{ Median Scores } \\
\hline \multicolumn{8}{|l|}{ Anxiety } \\
\hline No Anxiety & 41 & 38.0 & 10.0 & 11.0 & 6.0 & 1.0 & 8.0 \\
\hline Anxiety & 20 & 46.0 & 12.0 & 15.0 & 8.0 & 1.0 & 10.0 \\
\hline tp value & & $0.004^{*}$ & $0.032^{*}$ & $0.000^{*}$ & $0.032^{*}$ & 0.974 & $0.021^{*}$ \\
\hline \multicolumn{8}{|l|}{ Depression } \\
\hline No Depression & 46 & 39.0 & 11.0 & 12.0 & 6.0 & 1.0 & 8.0 \\
\hline Depression & 15 & 52.0 & 12.0 & 15.0 & 9.0 & 1.0 & 11.0 \\
\hline tp value & & $0.001^{*}$ & $0.033^{*}$ & $0.002^{*}$ & $0.002^{*}$ & 0.699 & $0.001^{*}$ \\
\hline
\end{tabular}

Higher score indicates higher burden, $\uparrow$ : Mann Whitney $\mathrm{U}$ test, $\mathrm{BR}=\mathrm{Burden}$ in relationship, $\mathrm{EW}=\mathrm{Emotional}$ Wellbeing, $\mathrm{SF}=\mathrm{Social}$ and Family life, Fl=Finances, LC=Loss of control over one's life, *: $p$-value significant at $\leq 0.05$

Table 4. Association between socio-demographic characteristics and burden across different domains $\mathrm{n}=61$.

\begin{tabular}{|c|c|c|c|c|c|c|c|}
\hline \multirow{3}{*}{ Socio-demographic variables } & \multirow{3}{*}{$\mathrm{n}$} & \multicolumn{6}{|c|}{ Domains of Zarit Burden Interview -22} \\
\hline & & Total Score & \multicolumn{2}{|c|}{ BR } & EW & SF & $\mathrm{FI}$ \\
\hline & & & & & & \multicolumn{2}{|c|}{ Median Score } \\
\hline \multicolumn{8}{|l|}{ Age (years) } \\
\hline$\leq 35$ & 43 & 39.0 & 11.0 & 13.0 & 7.0 & 1.0 & 10.0 \\
\hline$>35$ & 18 & 44.5 & 12.5 & 14.0 & 7.0 & 0.0 & 8.0 \\
\hline tp value & & 0.350 & 0.164 & 0.317 & 0.479 & 0.121 & 0.787 \\
\hline \multicolumn{8}{|l|}{ Educational Status } \\
\hline Less than secondary or secondary & 19 & 46.0 & 12.0 & 14.0 & 8.0 & 2.0 & 11.0 \\
\hline Higher secondary and above & 42 & 39.5 & 11.0 & 12.5 & 6.0 & 0.0 & 8.0 \\
\hline tp value & & $0.024^{*}$ & 0.567 & 0.090 & 0.095 & $0.004^{*}$ & $0.004^{*}$ \\
\hline \multicolumn{8}{|l|}{ Employment status } \\
\hline Unemployed & 36 & 40.5 & 11.0 & 13.5 & 7.0 & 1.0 & 9.0 \\
\hline
\end{tabular}


Perceived Burden in Caregivers of Children with Autism Spectrum Disorder

\begin{tabular}{|c|c|c|c|c|c|c|c|}
\hline Employed & 25 & 40.0 & 11.0 & 13.0 & 7.0 & 1.0 & 9.0 \\
\hline tp value & & 0.918 & 0.929 & 0.860 & 0.959 & 0.574 & 0.718 \\
\hline \multicolumn{8}{|c|}{ Age of child (years) } \\
\hline $0-10$ & 48 & 40.5 & 11.0 & 13.0 & 6.5 & 1.0 & 9.0 \\
\hline $10-19$ & 13 & 40.0 & 12.0 & 13.0 & 7.0 & 1.0 & 9.0 \\
\hline tp value & & 0.412 & 0.972 & 0.536 & 0.430 & 0.542 & 0.193 \\
\hline \multicolumn{8}{|l|}{ Sex of child } \\
\hline Male & 47 & 41.0 & 11.0 & 13.0 & 7.0 & 1.0 & 9.0 \\
\hline Female & 14 & 40.0 & 10.5 & 14.0 & 5.5 & 0.0 & 8.5 \\
\hline tp value & & 0.577 & 0.575 & 0.535 & 0.173 & 0.107 & 0.427 \\
\hline
\end{tabular}

Higher score indicates higher burden, $\uparrow$ : Mann Whitney $\mathrm{U}$ test, $\mathrm{BR}=\mathrm{Burden}$ in relationship, EW=Emotional Wellbeing, SF=Social and Family life, Fl=Finances, $L C=$ Loss of control over one's life, *: $p$-value significant at $\leq 0.05$

\section{DISCUSSION}

The children included in our study belong to school age group which is in line with the findings from other studies in which the mean age of the child lied in the same age group. ${ }^{16-21}$ The male is to female ratio in our study was found to be $3.4: 1$ which is supported by the findings obtained from other studies in which the ratio ranged from 2.3:1 to $3.3: 1 .{ }^{17,22,23}$ Various other studies carried out worldwide have found that the male is to female ratio is as large as $5: 1 .^{18}$ These finding suggest that significantly greater number of male children in our study suffer from ASD when compared to female. Our study found that mean age of diagnosis of ASD range from 1 to 13 years which can be compared to the findings obtained from another study carried out in Nepal in which it was found that the age of diagnosis ranged from 1 to 15 years. ${ }^{20}$ While comparing these two studies, it can be seen that the maximum age of diagnosis has decreased which might be because of the increasing awareness of ASD in Nepal.

Our study showed that, on average, caregivers experienced moderate to severe burden which is in line with the findings obtained in a study carried out in Nigeria. ${ }^{21}$ Our study also showed that around one third of the caregivers were anxious while similar number were depressed. The finding is supported by other literature reviewed in which one third of the caregivers of children with ASD had psychological distress which is mainly due to long term challenges of caregiving associated with ASD. ${ }^{23,24}$ Similarly, a study carried out in Saudi Arabia revealed that parents/caregivers of children with ASD have higher incidence of overall anxiety and depression due to the burden posed by the challenging child care demands. ${ }^{25}$

Our study showed that age of the caregiver is not significantly associated with burden which hints that handling a child with ASD is difficult for caregivers of any age. Most of the literature reviewed has also shown that age has no significant association with burden. 5,26 However, another study carried out in Canada revealed that parental age was associated with feeling of burden with older parents reporting greater burden. ${ }^{27}$ This dissimilar finding might have occurred because of differences in sample size and social values of Nepal and Canada.In our study, level of education was found to be significantly associated with overall burden and burden in finances and control of life. The caregivers with higher level of education were found to experience less burden than those with lower level. The results is similar to the findings obtained from other studies in which it has been found that objective burden like impact of child's disability on mother's finance, work, social and recreational activities decreased with increased years of education. ${ }^{26}$ Our study shows that status of employment was not significantly associated with burden which could be due to the fact that most of the caregivers were either homemakers or worked at Autism Care Nepal Society where they could take their child along with themselves and leave them with supervisors present at the day care center of the institution. The finding is consistent with the results obtained from other studies in which it has been reported that occupational status doesn't affect the perception of burden. ${ }^{15,28}$ However, another study conducted by Green ${ }^{26}$ reported that working mothers experienced higher burden due to the exaggerated demands of the child and challenging job responsibilities. This diverse finding might have occurred because of socio-economic differences between the two societies.

Our study shows that age and sex of the child has no significant association with burden perceived by the caregivers. This might be because in every age of the 
child there would always be some unique challenges associated with caregiving which is similar for either a boy or a girl child. These results are similar to the findings obtained from some other studies in which it has been found that age or sex of child doesn't affect the feeling of burden. ${ }^{15,26-28}$

Likewise, our study showed that the duration of diagnosis and status of training received has no significant association with burden of caregiving which is supported by the study carried out by Dada et al., ${ }^{15}$ and Divan et al. ${ }^{29}$ in which duration from diagnosis was not found to change the feeling of strain and worry about the child's future. Moreover, in our study, status of received training and hours spent on child care was not significantly associated with burden which is in accord with the study findings of Hastings and Johnson ${ }^{7}$ which reported that the efficacy of intervention training largely depend on the motivation of the caregivers before intervention and expectation from the treatment but not just the status of training received. Similarly, stress and depression were found to act as barrier to the efficacy of intervention training. ${ }^{30}$ Hence, it can be assumed that caregiver's emotional health and adherence to the intervention plays a significant role in the care of the children with ASD.

Our study revealed that overall burden and burden in all the domains except the financial domain is significantly associated with psychological distress i.e. anxiety and depression present in caregivers of children with ASD which is supported by the literature reviewed in which burden of caregiving was found to be associated with anxiety and depression present in caregivers of children with disabilities. ${ }^{15,31}$ In Nepal where diagnosis of ASD itself is very difficult, various expensive treatment modalities used in ASD are still unknown. So, there is a very less possibility that the anxiety and depression experienced by caregivers be due to financial burden. This might also have occurred because even when caregivers were depressed or anxious they might not have stopped working or earning.

\section{CONCLUSIONS}

Our study thus concluded that caregivers of children with ASD experience tremendous burden which is perceived by them as ranging from moderate to severe. Burden in all the areas of caregiving except the financial status was found to be significantly associated with anxiety and depression present in caregivers. Moreover, the level of education of caregivers significantly affect burden in finances and sense of control over caregiver's own life. Our study also concludes that it is important to understand complex issues like feeling of burden and psychological distress among caregivers of children with ASD as these findings might be useful to identify the areas that are affected by the burden of long term caregiving process and would help in understanding the feelings, beliefs, opinions and experiences of parents. Insights from the study would help in developing interventions focusing the needs of children with ASDs and their family.

\section{ACKNOWLEDGEMENTS}

The authors thank all the caregivers who participated in this study, Autism Care Nepal Society and Nursing Campus, Maharajgunj, Kathmandu, Nepal.

\section{REFERENCES}

1. American Psychiatric Association [APA]. Diagnostic and Statistical Manual of mental disorders V. In. 5th ed Arlington, Virginia: American Psychiatric Association. 2013.[Full Text]

2. Center for Disease Control and Prevention [CDC]. Autism Spectrum Disorder : Data \&Statistics. In. Atlanta, GA: Center for Disease Control and Prevention; 2014.[Full Text]

3. Shrestha M, Santangelo S. Autism: Challenge in Nepal. In: Patel VB, Preedy VR, Martin CR, editors. Comprehensive Guide to Autism: Springer New York. 2014. p. 2497-2507. [Full Text]

4. Chapagai M, Dangol KM, Tulachan P. A sudy of Psychiatric Morbidity amongst Children Attending a Child Guidance Clinic at a Tertiary Level Teaching Hospital in Nepal. Journal of Nobel Medical College. 2013;2(3):55-63.[Full Text]

5. Matson JL, Nebel-Schwalm M. Assessing challenging behaviors in children with autism spectrum disorders: A review. Res Dev Disabil. 2007;28(6):567-579. [Science Direct]

6. Schieve LA, Blumberg SJ, Rice C, Visser SN, Boyle C. The relationship between Autism and Parenting Stress. Pediatrics. 2007:S114-S121. [Full Text]

7. Hastings RP, Johnson E. Stress in UK Families Conducting Intensive Home-Based Behavioral Intervention for Their Young Child with Autism. J Autism Dev Disord. 2001;31(3):327-336. [PubMed]

8. Bashir A, Bashir U, Lone A, Ahmad Z. Challenges faced by families of Autistic Children. International Journal of Interdisciplinary Research and Innovations. 2014;2(1):64-68.[Full Text] 
9. Giallo R, Wood CE, Jellett R, Porter R. Fatigue, wellbeing and parental self-efficacy in mothers of children with an autism spectrum disorder. Autism. 2013;17(4):465-80. [PubMed]

10. Osborne LA, McHugh L, Saunders J, Reed P. Parenting stress reduces the effectiveness of Early Teaching Interventions for Autistic Spectrum Disorders. J Autism Dev Disord. 2008;38:1092-1103. [PubMed]

11. Fro ${ }^{\mathrm{j} d h} \mathrm{~K}, \mathrm{Ha}^{\circ}$ kansson A, Karlsson I. The Hopkins Symptom Checklist-25 is a sensitive case-finder of clinically important depressive states in elderly people in primary care. Int J Geriatr Psychiatry. 2004;19:386-390. [PubMed]

12. Thapa SB, Hauf E. Perceived needs, self-reported health and disability among displaced persons during an armed conflict in Nepal. Soc Psychiatry Psychiatr Epidemiol. 2012;47:589-595.[PubMed]

13. Nettelbladt P, Hansson L, Stefansson C-G, Borgquist L, Nordström G. Test characteristics of the Hopkins Symptom Check List-25 (HSCL-25) in Sweden, using the Present State Examination (PSE-9) as a caseness criterion. Soc Psychiatry Psychiatr Epidemiol. 1993;28(3):130-133. [PubMed]

14. Rankin E, Haut M, Keefover R, Franzen M. The establishment of clinical cutoffs in measuring caregiver burden in dementia. Gerontologist. 1994;34(6):828-32. [PubMed]

15. Dada MU, Okewole NO, Ogun OC, Bello-Mojeed MA. Factors associated with caregiver burden in a child and adolescent psychiatric facility in Lagos,Nigeria: a descriptive cross sectional study. BMC Pediatr. 2011;11(110). [PubMed]

16. Bello-Mojeed M, Omigbodun O, Ogun O, Adewuya A, Adedokun B. The relationship between the pattern of impairments in autism spectrum disorder and maternal psychosocial burden of care. OA Autism 2013;1(1):1-7. [Full Text]

17. Altiere MJ, Kluge Sv. Family Functioning and Coping Behaviors in Parents of Children with Autism. J child Fam Studies. 2009; 18:83-92. [Full Text]

18. Benson PR, Karlof KL. Anger, Stress Proliferation, and Depressed Mood Among Parents of Children with ASD: A Longitudinal Replication. J Autism Dev Disord. 2009;39:350-362.[PubMed]

19. Falk NH, Norris K, Quinn MG. The Factors Predicting Stress, Anxiety and Depression in the Parents of Children with Autism. J Autism Dev Disord. 2014;44(12):31853203. [PubMed]
20. Shrestha M, Shrestha R. Symptom Recognition to Diagnosis of Autism in Nepal. J Autism Dev Disord. 2013;44(6):1483-1485. [PubMed]

21. Al-Farsi YM, Waly MI, Al-Sharbati MM, Al-Shafaee M, Al-Farsi O, Al-Fahdi S, et al. Variation in socio-economic burden for caring of children with autism spectrum disorder in Oman: Caregiver Perspectives. J Autism Dev Disord. 2013;43:1214-1221. [PubMed]

22. Lee LC, Harrington RA, Louie BB, Newschaffer CJ. Children with autism: quality of life and parental concerns. J Autism Dev Disord. 2008;38:1147-1160. [PubMed]

23. Junior SBM, Celestino MIO, Serra JPC, Caron J, Ponde MP. Risk and protective factors for symptoms of anxiety and depression in parents of children with autism spectrum disorder. In: Developmental neurorehabilitation. 19 June 2014 ed. UK: Informa Healthcare; 2014. p. 1-8. [Full Text]

24. Charnsil C, Bathia N. Prevalence of Depressive Disorders among caregivers of the children with Autism in Thailand. ASEAN J Psychiatry. 2010;11(1).[PubMed]

25. Almansour MA, Alateeq MA, Alzahrani MK, Algeffari MA, Alhomaidan HT. Depression and anxiety among parents and caregivers of autistic spectral disorder children. Neurosciences. 2013;18(1):58-63. [Full Text]

26. Green SE. "We're tired, not sad": Benefits and burdens of mothering a child with a disability. Soc Sci Med. 2007;64:150-163. [PubMed]

27. Vogan V, Lake JK, Weiss JA, Robinson S, Tint A, Lunsky Y. Factors associated with caregiver burden among parents of individuals with ASD: differences across intellectual functioning. Fam Relat. 2014;63:554-567. [PubMed]

28. Nagaraju K, Wilson J. Burden and stress perceived by mothers having autistic children. International Journal of Multidisciplinary Research in Social \& Management Sciences. 2013;1(4):53-57. [Full Text]

29. Divan G, Vajaratkar V, Desai MU, Strik-Lievers L, Patel V. Challenges, coping strategies, and unmet needs of Families with a child with autism spectrum disorder in Goa, India. Autism Res. 2012;5:190-200.[PubMed]

30. Nock MK, Kazdin AE. Parent Expectancies for Child Therapy: Assessment and relation to participation in treatment. J Child Fam Stud. 2001;10(2).[Full Text]

31. Gallagher S, Phillips AC, Oliver C, Carroll D. Predictors of psychological morbidity in parents of children with intellectual disabilities. J Pediatr Psychol. 2008;33(10):1129-1136.[Full Text] 